\title{
Análise da trama de argumentos na obra "Meditações" cartesianas na construção da ideia do "Cogito": uma proposta para um modelo didático para o ensino de Filosofia
}

\section{An analysis of arguments schemes in the Cartesian "Meditations" in building the "Cogito" idea: proposing an educational model for Philosophy teaching}

\author{
Daniel Manzoni de Almeida ${ }^{1}$
}

\begin{abstract}
RESUMO
Uma das principais heranças do pensamento racionalista de René Descartes (1596-1650) está materializada no conceito do Cogito. A proposta aqui foi desenvolver uma análise dos principais argumentos dos dois primeiros textos clássicos da obra Meditações e expor a trama de argumentos que formam o corpo do conceito do Cogito com o objetivo de estruturar uma sequência didática. Na primeira parte do artigo está a exposição dos argumentos cartesianos dos sentidos, dos sonhos, do Deus enganador, de extensão como Dados; a ideia do Gênio maligno como Justificativa; e a Conclusão da ideia do Cogito: "penso, logo existo". A segunda parte está na construção da ideia do Cogito como modelo didático. A hipótese é que essa estrutura possa servir como prática didática nas aulas de Filosofia do ensino básico estimulando a argumentação e as discussões sobre a obra cartesiana.

Palavras-chaves: argumentação; ensino de argumentação; ensino de Filosofia.
\end{abstract}

\section{DOI: $10.1590 / 0104-4060.46423$}

1 Escola da Saúde, Centro Universitário das Faculdades Metropolitanas Unidas (FMU). São Paulo, São Paulo, Brasil. Rua Taguá, nº 150 - Liberdade. CEP: 01508-010. E-mail: danielmanzoni@yahoo.com.br 


\begin{abstract}
One of the main legacies of the rationalist thought of René Descartes (1596$1650)$ is embodied in the concept of Cogito. Here, the purpose was to develop an analysis of the main arguments in the classical texts of the first and second Meditations and expose the web of arguments that form the Cogito concept body in order to structure a teaching sequence. In the first part of the article is the exposure of Cartesian arguments of senses, dreams, the deceivable God, extension as Data; the idea of evil Demon as Justification; and the idea of the Cogito Conclusion: "I think, therefore I am". The second part is the Cogito idea construction as a teaching model. The hypothesis is that this structure can serve as teaching practice in primary school Philosophy classes stimulating argumentation and discussions about the Cartesian work.
\end{abstract}

Keywords: argumentation; argumentation teaching; Philosophy teaching.

\title{
Introdução
}

A argumentação faz parte das diversas linguagens do cotidiano. Na cultura filosófico-científica, ela está materializada, principalmente, nas categorias das linguagens escritas. Assim, no ensino de uma forma de conhecimento, a argumentação exerce um papel fundamental de ferramenta no processo de construção do saber e significado no campo educacional de uma área do pensamento, como por exemplo, a Filosofia.

Ao considerarmos as ciências humanas, exatas ou biológicas como produções sociais de aquisição intelectual, podemos inferir que a prática discursiva é uma regra central no processo de estabelecer conhecimentos. (DRIVER; NEWTON; OSBORNE, 2000). A modalidade argumentativa de linguagem se estabelece em inúmeros momentos da produção científica. Por exemplo, a partir de argumentos, os cientistas caminham da observação dos dados empíricos à experimentação na produção de hipóteses e, após essa fase, argumentam a partir dos resultados obtidos, como chegaram a determinada conclusão. A argumentação aqui é compreendida como a capacidade de conectar dados e conclusões. Essa prática envolve justificar afirmações, escolher entre posições conflitantes, entre evidências mais adequadas para cada caso e também a defesa social de conclusões pessoais e teóricas. (SADLER; ZEIDLER, 2004; JIMÉNEZ-ALEIXANDRE; DÍAZ DE BUSTAMANTE, 2003). O raciocínio argumentativo é relevante para o ensino, já que um dos fins da investigação filosófico-científica é a geração e a justificativa de enunciados e ações que buscam a compreensão da 
realidade, razão pela qual o ensino deveria dar a oportunidade de desenvolver, entre outras, a capacidade de raciocinar e argumentar.

Na disciplina de Filosofia podemos dividir a importância da argumentação em duas partes. A primeira comunga com a proposta do ensino de argumentação empregada no ensino das ciências, ou seja, por meio da produção oral ou textual dos argumentos produzidos por alunos. Essa primeira parte valoriza a produção de argumentos nas aulas de Filosofia como parte da proposta criadora de possibilidade de conceitos dos próprios alunos na sequência didática nas aulas de Filosofia como, por exemplo, na proposta de oficinas de conceitos dividida em partes, como a sensibilização dos estudantes pelo tema filosófico; a investigação dos conceitos pertinentes no tema abordado; e a produção dos conceitos pelos próprios alunos. E é nessa etapa que o ensino de uma estrutura argumentativa pode ser pertinente como proposta de comunicação materializada, de forma textual, do pensamento elaborado pelos alunos com o tema abordado. A "Oficina de Conceitos" é uma proposta metodológica do ensino de Filosofia, que se propõe:

[...] enfatizar seu caráter prático, para além de uma mera transmissão de conteúdos da história da filosofia ou mero treinamento de competências e habilidades supostamente identificadas com o pensamento filosófico. Falar em oficina de conceitos é falar da experimentação que remete ao novo, à criação [...]. (GALLO, 2007, p. 25-26).

Assim, essa proposta metodológica é caracterizada em quatro etapas. A primeira etapa é chamada de "Sensibilização". É uma etapa que concentra a atenção para o tema do trabalho a ser discutido. O objetivo dessa etapa é a sensibilização dos estudantes quanto ao tema a ser trabalhado na atividade. A segunda etapa é a "Problematização". Nessa etapa o tema proposto na atividade é transformado em um problema a ser investigado pelos alunos. É a etapa da formulação da pergunta que instigará e motivará a curiosidade dos alunos. A terceira etapa é a "Investigação". É a fase em que os alunos terão contato ou irão desenvolver metodologias (no caso filosóficas e teóricas) para responder a questão desenvolvida na etapa da problematização. A quarta etapa é a "Conceituação". Nessa etapa, já apresentados a uma temática problematizada e dispostos de metodologia teórica para investigação, os alunos são estimulados a criar ou recriar os conceitos propostos na atividade. (GALLO, 2007).

A outra forma de abordagem da argumentação na disciplina de Filosofia é por meio da possibilidade de análise dos textos filosóficos. A essa abordagem 
podemos acrescentar a utilização de uma ferramenta analítica de argumentos na capacidade de identificar e analisar a trama de argumentos que compõe um texto filosófico. Essa metodologia de análise de estrutura de argumentos dos textos filosóficos pode auxiliar no ensino de Filosofia para a educação de nível superior e ensino básico. Assim, como essa metodologia de análise pode ser construída, de forma didática, para o estudo das estruturas internas de um texto de Filosofia?

Para fundamentar essa proposta, busco as referências nos estudos das propostas didáticas do campo do ensino das ciências. A análise de argumentos tem sido utilizada em diversos estudos da didática científica. (JIMENEZ-ALEIXANDRE; RODRÍGUEZ; DUSCHL, 2000). A mais utilizada é a proposta por Stephen Toulmin (edição de 2006). Partindo da premissa de que a argumentação é uma prática humana, em sua obra intitulada "Os usos do argumento", o autor desenvolveu um padrão para a análise de argumentos que identifica, além dos elementos básicos que os compõem, as relações entre esses elementos. Os elementos básicos de um argumento, segundo tal padrão, são o dado, a conclusão e a justificativa. É possível apresentar um argumento contando apenas com estes elementos, em que a estrutura básica é: "a partir de um dado $\mathrm{D}$, já que J, logo C". Podemos, então, definir que os dados são os elementos que fundamentam as conclusões; as conclusões são as afirmações cujos méritos se procura estabelecer e são as justificativas que nos permitem entender o raciocínio utilizado na passagem de dado às conclusões.

A argumentação está presente em todos os pensamentos dos grandes pensadores da história da Filosofia. Neste artigo, escolho o pensamento de René Descartes para análise e articulação com o ensino de Filosofia devido à sua importância revolucionária no pensamento ocidental na idade moderna. $\mathrm{O}$ objetivo cartesiano com a proposta metodológica da dúvida metódica no ano de 1641 foi reconstruir os conhecimentos em bases certas e seguras. A proposta cartesiana influenciou, de forma avassaladora, toda a construção de uma nova forma do pensar científico - que ainda toca o mundo contemporâneo. A dúvida metódica, na obra Meditações, está estruturada em diferentes argumentos para a chegada na conclusão maior da obra cartesiana, a ideia Cogito - "penso, logo existo". Tomando a ideia do Cogito como um "grande argumento" cartesiano, aqui, irei tomar os argumentos propostos, na primeira meditação, para demonstrar, como Dados, como fundamentar as bases argumentativas que Descartes cultivou para Concluir um conhecimento claro e distinto, o Cogito.

Seria possível estruturar uma atividade didática para o ensino de Filosofia como, por exemplo, a explicação da ideia do Cogito cartesiano, que contemple as propostas de Toulmin? Os objetivos deste artigo foram: 1) identificar e expor 
os argumentos, na primeira meditação cartesiana, que foram usados para a construção do Cogito; 2) propor um modelo, baseado na estrutura da argumentação de Toulmim, para o ensino de Filosofia.

\section{Metodologia}

Este é um trabalho qualitativo realizado pela interpretação da Primeira Meditação, das Meditações de René Descartes. Esse texto foi escolhido como modelo de representação da estrutura argumentativa proposta, visto que é um dos textos mais importantes e expressivos do Racionalismo moderno. Assim, a análise foi realizada em duas etapas:

a) Foi realizada, por meio da análise textual, a exposição dos argumentos da Primeira Meditação do livro "Meditações" de René Descartes, presente na edição: DESCARTES, René. Meditações. São Paulo: Abril Cultural, 1983. (Coleção Os Pensadores). Essa edição foi escolhida por apresentar uma boa tradução oriunda do texto original; e também por ser uma edição amplamente utilizada nas aulas de Filosofia para o ensino superior e ensino básico. Quando necessário, foi consultado o texto original presente na edição francesa DESCARTES, René. Méditations métaphysiques. Paris: Flammarion, 2009;

b) Tomando como o argumento central da obra cartesiana nas Meditações Metafísicas a proposição do Cogito cartesiano "Penso, logo existo", os argumentos que sustentam e estruturam essa premissa da Primeira Meditação foram separados, dispostos e analisados segundo o padrão básico do argumento de Toulmin (2006): argumentos tomados como "Dados", ou seja, como parte da estrutura do argumento que comporta os fatos que estão presentes no argumento e que juntos levam à formulação de uma conclusão. Nesse caso a conclusão que tomo do pensamento cartesiano é a proposição do Cogito; A "justificativa" do argumento, ou seja, aquela que é usada como apoio e garantia para fazer ponte entre os dados e a conclusão; e a "Conclusão", parte da estrutura que representa a afirmação ou proposição formulada, derivada na estrutura, contendo dados, garantias e apoios do argumento. Aqui, foi considerada como a proposição do Cogito. 


\section{Resultados}

\section{A exposição dos argumentos no caminho para o "Cogito"}

Em O Discurso do Método (1641), René Descartes propõe um método, com regras certas que segundo ele levarão ao conhecimento verdadeiro de tudo aquilo que pode ser conhecido. Essas regras são quatro: a) a evidência racional, que se alcança pela indução; b) a análise, que propõe a decomposição de uma problemática em partes elementares para análise; c) a síntese, que parte dos elementos absolutos encontrados na análise; e d) o controle, enumeração completa dos elementos analisados e que devem ser revisados. Essas regras lógicas para chegar ao conhecimento influenciaram toda a construção da Filosofia e da ciência do ocidente. Essa lógica do método cartesiano pode ser traduzida de uma forma simples que consiste em obtenção de dados, por meio de observações de pontos de vistas da realidade, formulação de uma hipótese que pode ser testada, com experiências ou racionalmente, e derivação de uma conclusão, de caráter universal, que passa a ser a verdade materializada do conhecimento desvelado. Essa estrutura da busca pela verdade pode ser captada para a formulação da ideia do Cogito cartesiano. Entretanto, como essa ideia foi construída nessa lógica?

Descartes escreveu as Meditações (1641) após a publicação do Discurso do Método. Em dois de seus textos, Descartes transporta a nossa imaginação para duas imagens que usa para ilustrar em que bases está alicerçado todo o conhecimento construído até aquele momento. Na obra Princípios da Filosofia é ilustrado que o conhecimento é como uma árvore em que as raízes são metafísicas. Já na obra Meditações ele nos transporta para a imagem do conhecimento alicerçado como um edifício em que os blocos primeiros, os alicerces, estão no poder do conhecimento metafísico. Em ambos os textos, Descartes propõe a fragilidade desse conhecimento que foi construído em bases tão dubitáveis. Assim, nas Meditações, Descartes tem um objetivo claro e distinto que é expor a fragilidade de todo o conhecimento construído e propor o núcleo sustentador do edifício que pretende construir a partir de então do seu método, a dúvida metódica. Nos primeiros blocos do seu novo edifício, propõe uma avaliação de uma problemática insolúvel de que "[...] era preciso que eu tentasse com seriedade, uma vez na minha vida, livrar-me de todas as opiniões nas quais até o momento acreditara, e começar tudo novamente a partir dos fundamentos, se pretendesse estabelecer algo sólido e duradouro nas ciências". (DESCARTES, 1983, p. 249). O problema exposto por Descartes está no alicerce do edifício que o conhecimento foi construído. Toda essa estrutura, até então, estava suspensa em bases movediças, insustentáveis, enganadoras, que poderiam estar equivocadas, nos sentidos. Assim, Descartes assume a missão de "[...] com plena liberdade a 
demolir em geral todas as minhas antigas opiniões [...]”. (DESCARTES, 1983, p. 249) e "[...] destruição de todo o edifício, no inicio irei me aplicar nos princípios sobre os quais todas as minhas antigas opiniões estavam assentadas". (DESCARTES, 1983, p. 250). Nesse texto Descartes resgata a tradição cética-porém com uma nova proposta - e nos traz a questão central sobre seu novo método científico, a dúvida. A dúvida cartesiana tem um papel distinto da dúvida cética. Enquanto a dúvida cética no traz o questionamento e não a conclusão definitiva de algo para um real conhecimento, a dúvida metódica cartesiana é o núcleo sustentador da arquitetura da metodologia. É o instrumental para o racional, não é uma dúvida do senso comum, chega à radicalidade. E o uso dessa dúvida tem uma finalidade clara que é chegar a um conhecimento claro e distinto e que "[...] o menor indício de dúvida que eu nelas encontrar será suficiente para impelir-me a repelir todas". (DESCARTES, 1983, p. 250).

Em suma, a dúvida metódica é uma dúvida hiperbólica que opera sistematicamente de modo radical e universalizante. Mas, ao operar assim, de modo universalizante, a dúvida hiperbólica encontra seu limite. Nas sucessivas etapas de generalização, a dúvida natural vai enfraquecendo até, por fim, desaparecer: as instituições atuais da matemática, enquanto fato, são inquestionáveis. Ora, se inicialmente a dúvida hiperbólica consiste num exagero da dúvida natural pela aplicação da dúvida lógica, então, nas ideias matemáticas, onde desaparece a dúvida natural, a dúvida hiperbólica tentaria dissolver-se. (FORLIN, 2004, p. 22).

Para demonstrar seu método, Descartes o aplica ao longo das meditações para chegar a uma verdade clara e distinta. A grande verdade clara e distinta cartesiana já apresentada nas segundas meditações é o Cogito. Na primeira meditação Descartes nos apresenta a problemática da estrutura em que o conhecimento se encontra e uma proposta para a reconstrução dessa estrutura por meio da dúvida metódica, na segunda meditação explora o uso da metodologia no questionamento "Mas o que sou?" (DESCARTES, 1983, p. 262) e chega à conclusão de que "Uma coisa que pensa. Que é uma coisa que pensa? É uma coisa que duvida, que concebe, que afirma, que nega, que quer, que não quer, que imagina também que sente". (DESCARTES, 1983, p. 262). Porém, como Descartes, por meio de sua dúvida metódica, chegará a essa verdade clara e distinta? Para chegar à ideia do Cogito, Descartes nos leva por um caminho cênico, apresentando uma série de argumentos, em que personagens costuram a apresentação do "penso, logo existo". Essa afirmação paradigmática carte- 
siana está sustentada no terreno da hipótese que ele chama de Gênio Maligno (malin génie),

[...] mas existe alguém, nao sei quem, enganador muito poderoso e astucioso, que dedica todo seu empenho em enganar-me sempre. Não há então, dúvida alguma de que existo, se ele me engana; e, por mais que engane, nunca poderá fazer com que eu nada seja, enquanto eu pensar ser alguma coisa [...]. (DESCARTES, 1983, p. 258).

Ou seja, a radicalização cartesiana leva a sustentar o aparecimento dessa “personagem", o Gênio maligno, como um moderador metafísico do seu método científico, como um instrumento experimental importante na flexão e articulação da engrenagem articulatória do pensamento no caminho de uma verdade. Assim, nessa engrenagem, qual a consequência se a realidade fosse comandada por um gênio malicioso e que manifestasse sua esperteza e malícia em fazer com que todo o homem estivesse errado toda vez que tivesse a mais forte impressão de que estivesse certo? Ao levantar essa hipótese, Descartes coloca em xeque a objetividade de todo o conhecimento científico sobrando, então, apenas a conclusão, o conhecimento indubitável do Cogito: "E quanto mais se duvide, mais se repete, reforçando-se, a mesma experiência: se duvidar de que duvido, só posso fazê-lo pensando essa dúvida a respeito da própria dúvida inicial". (PESSANHA, 1999, p. 20).

Quais são os argumentos propostos por Descartes, na primeira e na segunda meditação, no caminho para a sua verdade clara e distinta?

Na primeira meditação podemos identificar três grandes argumentos que dão o suporte para a construção da hipótese do Gênio maligno: o argumento dos sentidos, o dos sonhos e o do Deus enganador.

O argumento dos sentidos é apresentado logo no início da primeira meditação como ponto de partida para a construção da dúvida; como confiar na veracidade do conhecimento que tem como base o que os sentidos oferecem?

Até o momento presente, tudo o que considerei mais verdadeiro e certo, aprendi-os dos sentidos ou por intermédio dos sentidos; mas às vezes me dei conta de que esses sentidos eram falazes, e a cautela manda jamais confiar totalmente em quem já nos enganou uma vez. (DESCARTES, 1983, p. 250). 
Para Descartes toda aquela informação que chegar pelos sentidos pode ser colocada em dúvida. Os sentidos enganam. A partir do momento em que se afastarem todos os sentidos, perde-se o mundo, porém não se perdem as matemáticas. As matemáticas são a perfeição e não são dubitáveis.

Completando o argumento dos sentidos, é apresentado em seguida um segundo argumento. $\mathrm{O}$ argumento do sonho. Por esse argumento, Descartes usa uma extensão do argumento dos sentidos, levando a audiência a analisar a consciência entre estar em vigília e no sonho. A realidade conhecida pelo homem está ancorada nos sentidos. Esses sentidos, por sua vez, podem confundir a realidade. A fronteira entre a realidade que se apresenta ou a realidade conhecida é questionada. Ou seja, no argumento do sonho, o imperativo é a questão: o que é a realidade?

[...] devo aqui ponderar que sou homem, e, consequentemente, que tenho hábito de dormir e de representar, em meus sonhos, as mesmas coisas ou algumas vezes menos prováveis, que esse dementes despertos. Quantas vezes me aconteceu sonhar, durante a noite, que me encontrava nesse lugar, vestido e próximo ao fogo, apesar de me achar totalmente nu em minha cama? Afigura-se-me agora que não é com os olhos adormecidos que olho para esses papéis, que essa cabeça que eu movo não se encontra adormecida; que é com intento deliberado que estendo essa mão e que a sinto: o que sucede no sono não parece ser tão claro nem inconfundível quanto tudo isso. Porém, meditando diligentemente sobre isso, recordo-me de haver sido muitas vezes enganado, enquanto dormia, por ilusões análogas. E, persistindo, nesta meditação, percebo, tão claramente que não existem quaisquer indícios categóricos, nem sinais bastante seguros por meio dos quais se possa fazer uma nítida distinção entre a vigília e o sono, que me sinto completamente assombrado: e meu assombro é tanto que quase me convence de que estou dormindo. (DESCARTES, 1983, p. 250-251).

No sonho e/ou na vigília o sensível é perdido, mas não se perde a extensão. Ou seja, a noção do material, o que mais tarde Descartes chamará de res-extensa.

A demonstração dos dados sobre os sentidos nos dois argumentos pela dúvida metódica faz o homem perder a mundo. Passa a viver em um mundo onde tudo não passa mais a fazer sentido. Com a perda das verdades antes concebidas e agora as estruturas abaladas, há alguma coisa que sobra dessa arquitetura rachada? Para Descartes, exprimir ao limite a dúvida faz algo sobrar como indubitável devido às características racionais presentes, as matemáticas, 
diferentemente das outras ciências como as médicas, a física e a astronomia, que demonstram conhecimentos até o presente momento não livres da dúvida metódica, "Portanto, quer eu esteja acordado, quer esteja dormindo, dois mais três formarão sempre o número cinco e o quadrado jamais terá mais que quatro lados; e não me parece que verdades tão evidentes possam ser suspeitas de alguma falsidade ou dúvida”. (DESCARTES, 1983, p. 252-253). Assim, Descartes teria chegado a uma verdade clara e distinta? Teria algo além das verdades das matemáticas que poderiam suscitar "[...] o menor indício de dúvida que eu nelas encontrar será suficiente para impelir-me a repelir todas [...]"? (DESCARTES, 1983, p. 250). É justamente nesse ponto que Descartes leva sua dúvida ao extremo, radicaliza a dúvida, a transformando em hiperbólica, quando apresenta um terceiro argumento na sequência da primeira meditação, o argumento do Deus enganador.

Esse argumento é radical e expõe uma única saída que será a formulação da hipótese do Gênio maligno. Voltarei a essa hipótese mais adiante. O argumento do Deus enganador apresenta uma proposta. E ela é distinta da ideia do Gênio maligno. Enquanto a ideia do Gênio maligno é um recurso metodológico que leva à descoberta da existência do ser-pensamento, da amplitude maior do pensamento, a proposta do Deus enganador será o alicerce para a justificação da verdade das matemáticas. Assim, esse último funciona, na rede de argumentação da primeira meditação cartesiana, como forma de salvar e legitimar as matemáticas como processos racionais primeiros e indiscutíveis do pensamento. A proposta do Deus enganador cartesiana sustenta a existência de um ser, um Deus - um com intenções malignas e enganadoras -, que faça o homem acreditar nessa verdade, porém, que essa verdade - a das matemáticas, onde $2+3$ sempre será igual a 5 -, caso existam outros mundos, não seja verdade em outros mundos. Ou seja, que o dois mais dois igual a quatro, válido nesse mundo, não seja igual em outro mundo. Dessa forma, essa verdade - clara e distinta - não seja verdadeira. Que esse pensamento seja causado por um Deus enganador que esteja fazendo ele acreditar nessa verdade.

[...] conservo em meu espírito a opinião de que existe um Deus que tudo pode e por quem fui criado e produzido tal como sou. Mas quem me poderá garantir que esse Deus não haja feito com que não existe terra alguma, céu algum, corpo extenso algum, figura alguma, lugar nenhum e que apesar disso, eu possua os sentimentos de todas essas coisas e que tudo isso não me pareça existir de forma distinta daquela que eu vejo? E, também, como suponho que algumas vezes os outros se enganam até mesmo nas coisas que eles julgam conhecer com maior certeza, pode 
suceder que Deus tenha desejado que eu me equivocasse todas as vezes que realizo a adição de dois mais três, ou enumero os lados de um quadrado, ou em que julgo alguma coisa ainda mais fácil do que isso [...]. (DESCARTES, 1983, p. 253).

A proposta do Deus enganador cartesiano encaixa-se perfeitamente na intenção de legitimar as matemáticas no campo da não dúvida, visto que o projeto cartesiano como um todo tem a intenção de alicerçar o conhecimento atrelado ao conhecimento numérico das matemáticas, como linguagem de uma realidade traduzida a um mundo. Ao jogar esse argumento das lutas de forças do duvidar da existência exata dos números matemáticos a uma possível outra realidade, Descartes radicaliza sua proposta levando a dúvida metódica para a dúvida hiperbólica, como se entregasse a existência e a verdade das matemáticas a um campo impossível de transpor na racionalidade humana, ou seja, a dúvida hiperbólica é a extrema radicalidade do racionalismo cartesiano.

Esses Dados observados por Descartes o fazem formular uma hipótese, a hipótese do Gênio maligno. Essa hipótese se apresenta no final da primeira meditação, como um pressuposto, uma chamada misteriosa no final de um ato teatral e cria expectativas para a audiência de como irá se desenrolar nas próximas meditações:

Presumirei, então, que existe não um verdadeiro Deus, que é a suprema fonte de verdade, mas um certo gênio maligno, não menos astucioso e enganador do que poderoso, que dedicou todo o seu empenho em enganar-me. Pensarei que o céu, o ar, a terra, as cores, as figuras, os sons e todas as coisas exteriores que vemos não passam de ilusões e fraudes que Ele utiliza para surpreender minha credulidade. (DESCARTES, 1983, p. 255).

Descartes irá apegar-se a essa hipótese que será o assoalho para a sua conclusão de uma verdade clara e distinta, "[...] permanecerei teimosamente apegado a esse pensamento; e se, por meio, não está em meu poder chegar ao conhecimento de qualquer verdade, ao menos está ao meu alcance suspender o juízo". (DESCARTES, 1983, p. 255). Essa teimosia cartesiana que está agarrado levará sua hipótese a desembocar na ideia do Cogito, na segunda meditação, quando Descartes conclui que existe um Gênio maligno que o tenta enganar constantemente, o fazendo achar que sua realidade não existe: "Eis porque cuidarei zelosamente de não receber de minha crença nenhuma falsidade, e preparei 
tão bem meu espírito contra todas as artimanhas desse grande enganador que seja, jamais poderá impor-me alguma coisa". (DESCARTES, 1983, p. 255).

É apegado a essa hipótese que Descartes faz a descoberta da relação do pensamento com o existir. É por meio dessa hipótese que ele chega a uma verdade clara e distinta em que "[...] um outro é pensar, e verifico aqui que o pensamento é um atributo que me pertence; somente ele não pode ser separado de mim. Eu sou, eu existo: isto é certo [...]". (DESCARTES, 1983, p. 261). Esse exercício o fará concluir que apenas o fato de já estar pensando nessa situação é porque existe:

Que é uma coisa que pensa? Uma coisa que duvida, que concebe, que afirma, que nega, que quer, que não quer, que imagina também, que sente. (DESCARTES, 1983, p. 262).

Nada admito agora que não seja obrigatoriamente verdadeiro: nada sou, então, a não ser uma coisa que pensa, ou seja, um espírito, um entendimento ou uma razão, que são palavras cujo significado me era anteriormente desconhecido [...]. (DESCARTES, 1983, p. 261).

Assim, o Gênio maligno, então, para Descartes, é como uma entidade ilusória que constantemente teria o papel de impor suas ilusões para crenças em realidades não existentes. Desse jogo de forças entre a atuação regadas a ilusões impostas e o exercício de superar essas falsas formas de realidade, o pensamento surgiria como a base de sustentação para o caminho da verdade por uma racionalidade pura humana.

\section{A construção do modelo didático para a ideia do Cogito cartesiano}

Tomando o padrão básico de um argumento proposto por Toulmim, podemos construir o caminho para a formulação da ideia do Cogito cartesiano como mostrado na Figura 1, tendo os Dados como argumentos dos sentidos, dos sonhos observados e formulados da hipótese cartesiana para concluir o Cogito. Diferente dos outros argumentos, a questão do Gênio maligno formulado por Descartes é uma hipótese. Essa hipótese está sustentada com o conjunto de argumentos já explicitados, dando uma Justificativa para a Conclusão do Cogito por Descartes.

Em conclusão, nos últimos anos, novas abordagens foram acrescentadas aos estudos sobre ensino e aprendizagem, dentre as quais se destaca o papel das 
diferentes linguagens e discursos que circulam na sala de aula. Assim, podemos considerar a linguagem como a forma principal de manifestação de uma cultura. Esperamos que a utilização de estruturas de linguagem, como a argumentação, possa auxiliar no ensino-aprendizagem de ideias complexas em sala de aula.

\section{FIGURA 1 - ARQUITETURA DA “IDEIA DO COGITO”}

Dados(1) Conclusão (3)

- Argumento dos sentidos

- Argumento dos sonhos

- Argumento do Deus Enganador

- Cogito $=$ penso, $\log 0$ existo

Justificativa (2)

\section{A hipótese do Gênio maligno}

FONTE: O Autor (2016).

Em 1 estão os Dados (os argumentos explicitados da primeira e segunda meditações); em 2 a Justificativa (o argumento do Gênio maligno explicitado da segunda meditação); em 3 a Conclusão (o Cogito explicitado da segunda meditação).

\section{REFERENCIAS}

DESCARTES, R. Meditações. São Paulo: Abril Cultural, 1983. (Coleção Os Pensadores). DESCARTES, R. Méditations métaphysiques. Paris: Flammarion, 2009.

DRIVER, R.; NEWTON, P.; OSBORNE, J. Establishing the norms of scientific argumentation in classrooms. Science Education. London, v. 84, p. 287-312, May 2000.

FORLIN, E. O papel da dúvida metafísica no processo de constituição do cogito. São Paulo: Associação Editorial Humanitas, 2004. 
GALLO, S. A filosofia e seu ensino: Conceito e transversalidade. In: SILVEIRA, R. J. T.; GOTO, R. (Org.). Filosofia no ensino médio: Temas, problemas e propostas. São Paulo: Loyola, 2007.

JIMÉNEZ-ALEIXANDRE, M. P.; DÍAZ DE BUSTAMANTE, J. Discurso de aula y argumentación en la clase de ciencias: Cuestiones teóricas y metodológicas. Enseñanza de las ciencias, Santiago de Compostela, v. 21, n. 3, p. 359-370, Nov. 2003.

JIMÉNEZ-ALEIXANDRE, M. P.; RODRÍGUEZ, A. B.; DUSCHL, R. A. "Doing the Lesson" or "Doing Science": Argument in High School Genetics. Science Education, v. 84 , p. 757-792, Nov. 2000.

PESSANHA, J. A. M. Os Pensadores: Descartes. São Paulo: Nova Cultural, 1999.

SADLER, T. D.; ZEIDLER, D. L. The Morality of Socioscientific Issues: Construal and Resolution of Genetic Engineering Dilemmas. Science Education, v. 88, p. 4-27, Jan. 2004.

TOULMIN, S. E. Os usos do argumento. São Paulo: Martins Fontes, 2006.

Texto recebido em 20 de abril de 2016. Texto aprovado em 22 de julho de 2016. 